\title{
Bone Marrow Lymphoplasmacytic Infiltration of Less than 10\%
}

National Cancer Institute

\section{Source}

National Cancer Institute. Bone Marrow Lymphoplasmacytic Infiltration of Less than

10\%. NCI Thesaurus. Code C150568.

A morphologic finding indicating the presence of a lymphoplasmacytic infiltrate in the bone marrow, comprising less than $10 \%$ of the cellular population. 